\title{
Os Componentes do Ambiente Interno e Externo na Geração da Inovação nas Organizações.
}

\author{
Cibele Roberta Sugahara \\ Pontifícia Universidade Católica de Campinas \\ cibelesu@puc-campinas.edu.br \\ Celeste Aída Sirotheau Corrêa Jannuzzi \\ Pontifícia Universidade Católica de Campinas \\ celeste.jannuzzi@puc-campinas.edu.br \\ Orandi Mina Falsarella \\ Pontifícia Universidade Católica de Campinas \\ orandi@puc-campinas.edu.br
}

recebido em 20 de fevereiro de 2017

aprovado em 26 de fevereiro de 2018

\begin{abstract}
Resumo: Esse trabalho tem como objetivo relacionar e analisar os componentes do ambiente interno e externo à empresa que contribuem para a geração da inovação nas organizações e consequentemente para aumentar a competitividade. A construção dessa discussão é fundamentada em um levantamento bibliográfico sobre a inovação e a importância dos componentes do ambiente interno e externo das organizações. Os componentes do ambiente são listados como ambiente econômico, legal e regulatório, estrutura adequada para a inovação, trabalho de equipe com indivíduos-chave, entre outros. Como resultados, observase que o reconhecimento da necessidade das empresas em adequar suas estruturas organizacionais a fim de garantir maior interação entre funções e especialistas funcionais de várias áreas da empresa e não apenas de $\mathrm{P} \& \mathrm{D}$. Como a inovação provoca impacto tecnológico e econômico no mercado e nas organizações, o que envolve desde os insumos empregados para a sua geração até o seu padrão de consumo, alinhar estruturas organizacionais existentes aos componentes do ambiente pode promover a competitividade.
\end{abstract}

Palavras-chave: Inovação. Competitividade. Componentes do ambiente.

\section{Introdução}

No momento atual as organizações concentram esforços na busca por condições mais adequadas de competitividade. A competitividade, segundo Coutinho e Ferraz (1995), constitui-se como a capacidade da empresa em elaborar e implementar estratégias concorrenciais, que lhe permita manter uma posição sustentável no mercado. Ela se apresenta estreitamente relacionada com o desempenho da organização no mercado ou com a eficiência técnica em processos produtivos, traduzidas pelas características oferecidas por uma empresa ou um produto. Assim, na busca de competitividade cada produtor se esforça para criar e renovar vantagens competitivas e obter peculiaridades que o diferencie dos demais.

Revista da Micro e Pequena Empresa, Campo Limpo Paulista, v.12, n.1 p.51-66, 2018 ISSN 1982-2537 
A inovação assume papel fundamental nas organizações por permitir que as empresas se revigorem a partir da reestruturação de processos produtivos e/ou o desenvolvimento de produtos novos ou aperfeiçoados que possam melhorar o seu desempenho competitivo. Neste contexto, Coutinho e Ferraz (1995) afirmam que a inovação é indispensável para sustentar a competitividade em um ambiente de acirramento da concorrência, bem como para organizar o setor industrial para o contexto de retomada de crescimento. A partir deste entendimento, considera-se que a inovação é um recurso importante para a competitividade no sentido de superar as deficiências e necessidades potenciais de uma organização.

Entretanto, o que a princípio pode parecer simples ganha complexidade ao se constatar que a inovação nas organizações é construída a partir de predicativos oriundos do seu ambiente interno e externo. Essa construção pode ser exemplificada nas palavras de Albert (2002) quando afirma que a criação da inovação decorre de componentes do macrocontexto das organizações e lista esses componentes como: o ambiente econômico; a abertura da economia; o ambiente legal e regulatório; a educação e as pessoas; a política de inovação e os programas e as estruturas de $\mathrm{P} \& \mathrm{D}$.

Na literatura, além de Aubert (2002) outros autores como Tidd et. al (2008) propõem um conjunto de componentes do ambiente interno e externo à empresa que possam ser utilizados na criação de um ambiente propício à inovação. Esse conjunto de componentes é apresentado pelos autores como: (1) visão compartilhada, liderança e desejo de inovar; (2) estrutura adequada; (3) indivíduos-chave; (4) trabalho de equipe eficaz; (5) desenvolvimento individual contínuo e amplo; (6) comunicação expressiva; (7) inovação de alto envolvimento; (8) foco externo; (9) ambiente criativo; (10) organizações que aprendem.

Tidd et. al (2008) afirmam que não se pode considerar a questão da inovação sem a criação e a manutenção de um contexto organizacional inovador. Tal contexto abrange a estrutura e cultura subjacente - considerando o padrão de valores e crenças que suportam a inovação. Nesse sentido, é necessário relacionar competitividade com inovação. A discussão desse cenário requer a habilidade das empresas em incorporar a inovação no âmbito da estratégia corporativa.

As organizações lidam com componentes do ambiente para eliminar a burocracia sufocante, as estruturas inúteis, as paredes que limitam a comunicação e outros componentes que dificultam a passagem de boas ideias para a geração da inovação. É nesse contexto, que Tidd et al. (2008) justificam que uma organizarão inovadora é mais do que lidar com uma estrutura; trata-se de monitorar um conjunto integrado de componentes que juntos podem criar e fortalecer o tipo de ambiente inovador. Para tanto, faz-se necessário determinar a organização mais apropriada dadas as especificidades dos componentes do ambiente que a envolve.

Assim, sob esse ponto de vista, observa-se que para a construção da inovação em uma organização é de suma relevância que se considere os predicativos que constituem esse ambiente. As diferentes perspectivas no contexto em que uma organização está inserida afetam a geração da inovação. Considerando que a inovação é influenciada por componentes do ambiente interno e externo é que se apresenta o seguinte problema: Como os componentes oriundos do ambiente interno e externo da organização influenciam a geração da inovação?

Desse modo, visando discutir sobre a importância desses componentes para a inovação nas organizações é que se apresenta esse trabalho, com o objetivo de relacionar e analisar os componentes oriundos do ambiente interno e externo da organização que contribuem para a geração da inovação e consequentemente para aumentar a competitividade.

A construção dessa discussão é fundamentada em um levantamento bibliográfico sobre a inovação e os componentes do ambiente interno e externo da organização. Os resultados trazem uma análise dos componentes do ambiente evidenciando sua importância para a inovação nas organizações.

Revista da Micro e Pequena Empresa, Campo Limpo Paulista, v.12, n.1 p.51-66, 2018 ISSN 1982-2537 


\section{Inovação}

Nos estudos no campo da inovação recorre-se ao trabalho de Schumpeter (1977), um dos pioneiros a conceituar a inovação como elemento propulsor da competitividade das empresas. Nas concepções de Schumpeter (1977) as empresas procurarão fazer uso de inovação - um novo produto/serviço ou um novo processo para produzi-lo - a fim de obter vantagem competitiva. Ele orienta que a inovação tome por base o conceito de invenção, pelo fato da invenção incorporar uma ideia, um esboço ou um modelo para um dispositivo, produto, processo ou sistema novo ou aperfeiçoado. Com base nessa teoria, ele apresenta a inovação como a inserção da invenção numa transação comercial com a intervenção do novo produto, processo, sistema ou dispositivo na economia. Haveria, assim, para o autor, a possibilidade das empresas em desfrutar de vantagem competitiva por meio da inovação até o momento da criação de uma outra inovação. Em outras palavras, a inovação condiciona a dinâmica de reorganização da atividade econômica.

Nessa mesma perspectiva, a Organização para a Cooperação Econômica e Desenvolvi mento no Manual Frascati (OCDE, 2002), apresenta a inovação como a implementação de um produto (bem ou serviço) novo ou significativamente melhorado, ou um processo, ou um novo método de marketing, ou de um novo método organizacional nas práticas de negócios, na organização do local de trabalho ou nas relações externas. O processo de implementar algo novo ou significativamente melhorado no mercado tem como alicerce os componentes internos e externos à empresa (Kim, 2005, p. 30).

Partindo do pressuposto de que as organizações estão inseridas num espectro de possibilidades tecnológicas e de mercado oriundas, por exemplo, do crescimento da ciência, da tecnologia e do mercado mundial, o desafio é lidar com a inovação num ambiente de alta incerteza e velocidade de mudança dado que o desenvolvimento da inovação não é livre ou arbitrário, mas historicamente circunscrito. Freeman e Soete (2008, p. 458) expõem que o desafio para as empresas parece consistir em desenvolver capacidade de sobrevivência e crescimento a partir da capacidade em adaptar-se aos componentes do ambiente externo em rápida mudança, e de mudá-lo. Bessant e Tidd (2009) afirmam que a inovação para ser eficiente depende de como a organização seleciona e gesta seus projetos, como orienta esforços para coordenar recursos e insumos de diferentes funções do ambiente. Acredita-se que atender ao desafio apresentado por Freeman e Soete (2008) e Bessant e Tidd (2009) propiciaria condição para a competitividade das empresas. Langrish et al. (1972) propõem que se considere o contexto gerador da inovação decorrentes da: (1) demanda de mercado; (2) ciência. Nessa perspectiva, os autores destacam duas abordagens teóricas que impulsionam a inovação: a teoria da inovação impulsionada pela ciência (science-push) e a teoria da inovação induzida pela demanda (demand-pull). O contexto gerador e as aplicações da inovação dessas abordagens teóricas são apresentados no quadro 01:

Quadro 01 - Abordagens teóricas da inovação

\begin{tabular}{l|l|l}
\hline \multicolumn{1}{c|}{ Teorias da Inovação } & \multicolumn{1}{c|}{ Contexto Gerador da Inovação } & \multicolumn{1}{c}{ Aplicações da Inovação } \\
\hline $\begin{array}{l}\text { Impulsionada pela ciência } \\
\text { (science-push) }\end{array}$ & $\begin{array}{l}\text { Conhecimento Científico e Tecnológico } \\
\text { resultante da atividade de pesquisa para o } \\
\text { desenvolvimento de um produto ou processo } \\
\text { novo ou aperfeiçoado }\end{array}$ & $\begin{array}{l}\text { Aplicações finais nem sempre } \\
\text { previstas pelos usuários } \\
\text { potenciais ou cientistas que a } \\
\text { desenvolvem }\end{array}$ \\
\hline $\begin{array}{l}\text { Induzida pela demanda } \\
\text { (demand-pull) }\end{array}$ & $\begin{array}{l}\text { necessidade/demanda de mercado ou de um } \\
\text { mercado potencial para um produto ou } \\
\text { processo novo ou aperfeiçoado }\end{array}$ & $\begin{array}{l}\text { Aplicações orientadas por } \\
\text { problemas reais das empresas }\end{array}$ \\
\hline
\end{tabular}

Fonte: Langrish et. al, (1972) apud Freeman e Soete (2008). 
A teoria da inovação impulsionada pela ciência (science-push) envolve o reconhecimento de uma necessidade ou, por assim dizer de um mercado potencial para um novo produto ou processo. Ela depende também de "conhecimento técnico, o qual geralmente pode estar disponível, mas que também inclui com frequência os conhecimentos científicos e tecnológicos resultantes de atividades de pesquisa original" (Freeman \& Soete, 2008, p. 347). Em particular, a inovação impulsionada pela ciência como, por exemplo, o raio laser ou a energia nuclear, culminaram em resultados e aplicações finais que nem os usuários potenciais ou cientistas que participaram do trabalho original imaginaram.

$\mathrm{Na}$ teoria da inovação induzida pela demanda a inovação é orientada por problemas reais de produção das empresas. Pode ser originária de empresas privadas, do governo ou de consumidores domésticos. São exemplos de inovação induzida pela demanda: a borracha sintética, o processo de craqueamento ou o descaroçador de algodão, os quais surgiram de necessidades de mercado reconhecidas que levaram às invenções e posteriormente às inovações (Freeman \& Soete, 2008).

Com base nessas teorias, pode-se dizer que a inovação representa a primeira aplicação ou produção comercial de um novo processo ou produto. Mesmo assim, há que se questionar até que ponto os empresários vinculam as novas ideias ao mercado, ou até mesmo a algo previamente existente. É fato que em alguns casos, uma nova descoberta científica gera um mercado sem qualquer adaptação ou desenvolvimento adicional. Por isso, as inovações situam-se em algum lugar entre estes dois caminhos e "envolve alguma combinação imaginativa de novas possibilidades técnicas e de mercado" (Freeman \& Soete, 2008, p. 347$348)$.

Os estudos e as teorias sobre inovação evoluíram como pode ser visto nos trabalhos de Nelson \& Winter (1982) e Nelson (1993), OCDE (1995) entre outros. Nelson \& Winter (1982) apresentam a abordagem evolucionista da inovação, compreendida como um processo dependente da trajetória, pelo qual desenvolve-se o conhecimento e a tecnologia considerando a interação entre vários atores e fatores. Nelson (1993) apresentam a abordagem dos sistemas de inovação, cuja ênfase é dada à "influência das instituições externas, definidas de forma ampla, sobre as atividades inovadoras das empresas e outros atores" (OCDE, 1995, p. 40-41).

A inovação como afirma Laplane (1997, p.60) "deflagra um processo de destruição das estruturas econômicas existentes e de criação de novas estruturas". Este processo, por sua vez, tem como ponto focal a reorganização das condições de competitividade no ambiente das empresas. Isso porque a inovação afeta ou até mesmo rompe a estrutura industrial e econômica existente ao indicar uma nova ordem.

A inovação gera a necessidade de reorganização das condições de competitividade e adaptação dos agentes econômicos às condições estruturais dadas ou de iniciativas no intuito de propiciar vantagem competitiva em relação aos concorrentes. A vantagem competitiva perdura enquanto os concorrentes não conseguirem imitar ou superar a inovação introduzida no mercado (Laplane, 1997). Pelas palavras de Porter (1999) a inovação é considerada, para muitas empresas, a principal estratégia competitiva de sobrevivência e de crescimento, ampliando a possibilidade de aproveitar as oportunidades de mercado e gerar vantagem competitiva. Diante dessas colocações, quando se trata de obter vantagem competitiva por meio da inovação o desafio é reorganizar as condições de competitividade do ambiente organizacional. Para analisar como se relacionam os componentes oriundos do ambiente interno e externo da empresa na geração da inovação é importante considerar a inovação no ambiente competitivo das empresas.

Ross (2007) enfatiza que são poucas as organizações que mantêm a inovação permanente ao longo do tempo, segundo o autor os estudiosos sobre inovação aconselharam as empresas a buscarem a inovação do lado de fora da organização para gerar vantagem competitiva. Neste sentido, Arbix e Miranda (2017) afirmam que a inovação não suporta Revista da Micro e Pequena Empresa, Campo Limpo Paulista, v.12, n.1 p.51-66, 2018 ISSN 1982-2537 
interrupções, isso porque a instabilidade impacta significativamente seus resultados e drena seu ímpeto. São atividades intensivas em conhecimento, oriundas de redes que ultrapassam fronteiras e que possuem temporalidade própria.

Dessa forma, Ross (2007) argumenta ser importante que as empresas orientem suas competências principais - fabricação, administração de marca, distribuição entre outras enquanto buscam as inovações necessárias para o seu crescimento e competitividade, a partir de aquisições e parcerias. As organizações também podem ser guiadas a desenvolver cultura e processos internos capazes de desencadear internamente novas ideias e, dessa forma, evitar investimentos externos. Para Ross (2007), as novas ideias pressionam no sentido de testar a estratégia da empresa e de ampliar as alternativas disponíveis, o que reforça a capacidade adaptativa da empresa.

Coutinho \& Ferraz (1995) destacam que as empresas inseridas em mercados estagnados acabam introduzindo inovações pontuais, substituindo seus equipamentos apenas em momentos críticos do processo produtivo e adotando parcialmente novos métodos de trabalho. A inovação desenvolvida de forma contínua pode criar oportunidades e manter a competitividade das empresas.

Dessa maneira, pode-se dizer que o processo de desenvolvimento contínuo da inovação depende, entre outros fatores, da forma como a organização lida com a atividade de Pesquisa e Desenvolvimento (P\&D). Beaulieu (2013) argumenta que a inovação é uma atividade coletiva, sistêmica, contínua e cumulativa, e de natureza incerta. A ênfase a incerteza é explicada considerando que a inovação pode ser resultado da iniciativa privada no anseio de atender o mercado, e não apenas resultado direto ou indireto de atividades de Pesquisa e Desenvolvimento.

Chesbrough (2007) destaca que o setor interno de Pesquisa e Desenvolvimento já foi considerado um ativo estratégico nas empresas. A P\&D interna era valorizada quando se tratava do desenvolvimento e comercialização de um produto complexo. Isso permitiu a criação de pólos de conhecimento que colaboraram para o desenvolvimento de itens críticos da geração da inovação.ao desenvolvimento da inovação. Mais recentemente, têm-se notado um enfoque voltado ao exterior em $P \& D$. Ele ressalta a importância da tecnologia externa para impulsionar o setor de $\mathrm{P} \& \mathrm{D}$, bem como identificar oportunidades em que outras empresas possam utilizar sua tecnologia nos próprios negócios.

Dentro desse contexto, pode-se afirmar que os motivos que levam as empresas ao desenvolvimento da inovação de forma contínua são variados. O Manual de Oslo da OCDE (2005) mostra que os motivos das empresas que buscam a inovação podem envolver desde o interesse em produtos, mercados, eficiência, qualidade ou capacidade de aprendizado e de implementação de mudanças. Assim, conhecer os motivos que levam as empresas a inovar "auxilia o exame das forças que conduzem as atividades de inovação, tais como a competição e as oportunidades de ingresso em novos mercados" (OCDE, 2005, p. 26).

Diante do exposto, acredita-se que a configuração da estrutura organizacional e os fatores macroeconômicos têm grande relevância para a geração da inovação. Segundo o Manual de Oslo da OCDE (2005) as atividades de inovação podem ser impedidas por diversos fatores. Pode existir motivos para que as atividades de inovação não sejam iniciadas e/ou fatores que refreiam ou interfiram negativamente o seu desenvolvimento. Dentre os fatores que interferem na geração da inovação destacam-se: "os econômicos, como custos elevados e deficiências de demanda; os específicos a uma empresa, como a carência de pessoal especializado ou de conhecimentos, e os fatores legais, regulações ou regras tributárias" (OCDE, 2005, p. 26).

Estudos sobre os componentes do ambiente - econômicos, educacionais, políticas, socioculturais, tecnológicos e legais para a geração da inovação têm sido desenvolvidos por diversos autores como Cooperação e Desenvolvimento Econômico [OCDE], 2005; Tidd,

Revista da Micro e Pequena Empresa, Campo Limpo Paulista, v.12, n.1 p.51-66, 2018 ISSN 1982-2537 
2001; Aubert 2002, Ribeiro e Cherobim (2017), entre outros. O estudo recente de Ribeiro e Cherobim (2017) pondera que as especificidades e particularidades do ambiente interno e externo à organização para a geração da inovarão apresenta complexidade, incerteza, instabilidade e volatilidade. (Ribeiro e Cherobim (2017).

Segundo Ribeiro e Cherobim (2017) a proposta de interação entre ambiente e inovação, por meio de estudos sobre os componentes do ambiente que contribuem para a inovação é apresentada como uma possível solução para estreitar a lacuna entre pesquisa teórica e prática. Ressaltam que na maioria dos estudos a interação entre o contexto do ambiente para a geração da inovação é pouco explorada devido à falta de conhecimento dos componentes do ambiente.

O Manual de Oslo da OCDE (2005) ao tratar do cenário da inovação em países em desenvolvimento apresenta os seguintes fatores do ambiente que configuram o cenário da inovação nesses países:

incerteza macroeconômica; instabilidade; infra-estrutura física; fragilidade institucional; ausência de consciência social sobre a inovação; natureza empresarial de aversão ao risco; falta de empreendedores; existência de barreiras aos negócios nascentes; ausência de instrumentos de políticas públicas para dar suporte aos negócios e para o treinamento gerencial (OCDE, 2005, p. 155).

Assim, pressupõe-se que a necessidade de considerar as especificidades e particularidades do macrocontexto do ambiente na geração da inovação determina a condição de competitividade das organizações.

Segundo Tidd $(1997,2001)$ a insegurança do ambiente influencia tanto a magnitude quanto a duração da inovação. Damanpour (1996) e Tidd (2001) sugerem que os estudos sobre inovação adotem teorias de inovação organizacional sensíveis aos fatores do ambiente, controlando explicitamente o grau e a duração da incerteza do ambiente. Diante da incerteza do contexto do ambiente macroeconômico, Tidd et al. (2008) afirmam que a incerteza restringe qualquer atividade de inovação a longo prazo.

Por isso é importante analisar a influencia dos componentes do ambiente na geração da inovação de acordo com as condições de competitividade específicas de cada setor e país. Para Tidd et al. (2008) os agentes econômicos podem reunir condições suficientes para lidar com as novas condições de competitividade na geração da inovação adaptando-se a elas ou tentando mudá-las a seu favor. De forma mais incisiva, argumentam sobre a importância em analisar os componentes do ambiente para que a inovação prospere, visto que eles nem sempre são apreendidos de forma consensual.

Em complemento, Arbix (2017) afirma que a inovação deve ser considerada um recurso essencial para elevar o patamar da produtividade das organizações, por meio de iniciativas específicas para cada setor, como parte do esforço para aproximar a produtividade das empresas aos níveis apresentados por países que atuam na fronteira. No caso brasileiro, Arbix (2017) sugere a adoção de programas de inovação voltados para a demanda e com foco em resultados. Isto é, a adoção de programas ou instrumentos de inovação que apoiem os setores industriais, empresas e centros de pesquisa a desenvolver a inovação de forma integrada.

Diante das colocações anteriores, esse trabalho apresenta uma relação e análise dos principais componentes do ambiente interno e externo à empresas que contribuem para a geração da inovação listados a partir da categorização de Aubert (2002), como: (1) econômico; (2) abertura da economia; (3) ambiente legal e regulatório; (4) educação e pessoas; (5) política de inovação; (6) programas e estruturas de P\&D, (Quadro 02).

Quadro 02 - Componentes do ambiente que contribuem para a geração da inovação. 


\begin{tabular}{l|l}
\hline \multicolumn{1}{c|}{ Componentes } & \multicolumn{1}{c}{ Exemplos } \\
\hline Econômicos & Inflação; taxa de juros; política industrial \\
\hline Abertura da economia & $\begin{array}{l}\text { Modernização tecnológica da indústria; importação de bens; } \\
\text { exposição do mercado interno ao mercado internacional }\end{array}$ \\
\hline Ambiente legal e regulatório & Sistema legal nacional \\
\hline Educação e Pessoas & Nível educacional da população \\
\hline Política de inovação & $\begin{array}{l}\text { Política de inovação que considere as condições de competitividade } \\
\text { das empresas no mercado interno e externo }\end{array}$ \\
\hline Programas e Estruturas de P\&D & Esforço de investimento público e privado para inovação \\
\hline
\end{tabular}

Fonte: Elaborado a partir de Aubert (2002).

Tidd et. al. (2008), também apresentam uma relação de fatores do ambiente interno e externo à organização que interferem na geração da inovação, categorizados como: (1) visão compartilhada, liderança e desejo de inovar; (2) estrutura adequada; (3) indivíduos-chave; (4) trabalho de equipe eficaz; (5) desenvolvimento individual contínuo e amplo; (6) comunicação expressiva; (7) inovação de alto envolvimento; (8) foco externo; (9) ambiente criativo; (10) organizações que aprendem (Quadro 3).

Quadro 03 - Fatores do ambiente que contribuem para a geração da inovação.

\begin{tabular}{l|l}
\hline \multicolumn{1}{c|}{ Fatores } & \multicolumn{1}{c}{ Características-chave } \\
\hline $\begin{array}{l}\text { Visão compartilhada, liderança } \\
\text { e desejo de inovar }\end{array}$ & $\begin{array}{l}\text { Propósito claramente compartilhado e articulado "comprometimento da } \\
\text { alta gestão" }\end{array}$ \\
\hline $\begin{array}{l}\text { Estrutura adequada } \\
\text { Indivíduos-chave }\end{array}$ & $\begin{array}{l}\text { Projeto de organização que incentive a criatividade, a aprendizagem e a } \\
\text { interação. }\end{array}$ \\
\hline Trabalho de equipe eficaz & $\begin{array}{l}\text { Pessoas que promovam, defendam e estejam envolvidas com o processo de } \\
\text { inovação } \\
\text { Uso adequado de equipes para solução de problemas. Exige investimento }\end{array}$ \\
\hline $\begin{array}{l}\text { Desenvolvão e formação de equipe } \\
\text { contínuo e amplo }\end{array}$ & $\begin{array}{l}\text { Compromisso de longo prazo com ensino e treinamento para assegurar } \\
\text { altos níveis de competência e habilidades para aprender eficazmente }\end{array}$ \\
\hline
\end{tabular}

Revista da Micro e Pequena Empresa, Campo Limpo Paulista, v.12, n.1 p.51-66, 2018 ISSN 1982-2537 


\begin{tabular}{|c|c|}
\hline Comunicação extensiva & Comunicação entre as pessoas da organização e entre organizações \\
\hline Inovação de alto envolvimento & Participação de toda a organização em atividades de melhoria contínua \\
\hline Foco externo & Orientação do cliente externo e interno. Extensivo trabalho entre empresas \\
\hline Ambiente criativo & $\begin{array}{l}\text { Abordagem positiva a idéias criativas, apoiadas por sistemas de motivação } \\
\text { relevantes }\end{array}$ \\
\hline Organizações que aprendem & $\begin{array}{l}\text { Intenso envolvimento dentro e fora da empresa em experimentação pró- } \\
\text { ativa, encontrando e resolvendo problemas; comunicação e } \\
\text { compartilhamento de experiências e captura e disseminação de } \\
\text { conhecimento }\end{array}$ \\
\hline
\end{tabular}

Fonte: Elaborado a partir de Tidd et al. (2008).

A partir dos componentes apresentados por Aubert (2002) e Tidd et al. (2008), sintetizase a relação de componentes que fazem parte da análise, a saber: ambiente econômico e ambiente legal e regulatório; educação e desenvolvimento individual; indivíduos chave; organizações que aprendem; inovação com envolvimento das pessoas; trabalho em equipe; visão compartilhada, liderança e desejo de inovar; ambiente ou atmosfera criativa; comunicação extensiva; programas de P\&D e estrutura organizacional adequada (Quadro 4).

\section{Análise dos Componentes do Ambiente Interno e Externo na Geração da Inovação.}

A análise dos componentes do ambiente para a geração da inovação nas organizações contribui para contextualizar as condições essenciais do ambiente para a inovação. Os aspectos do ambiente elencados por Aubert (2002), podem ser utilizados para definir ações voltadas para a inovação nas organizações.

Os componentes econômicos como, por exemplo, a baixa taxa de inflação e a baixa taxa de juros são essenciais para indicar investimentos direcionados à inovação, que envolvem mais riscos do que outros tipos de investimento (Aubert, 2002). Pode-se dizer que que a vulnerabilidade da economia às crises financeiras internacionais e a incerteza causada pela movimentação de entrada e saída de capital é um desafio permanente devido à insuficiente competitividade estrutural das organizações.

Para Coutinho e Ferraz (1995) em busca de condições de competitividade solida é necessário aplicar tarifas que incitem a produção local de novos produtos, componentes e peças em condições de competitividade ou que resguardem a produção ameaçada pela concorrência desleal, a imposição temporária de direitos compensatórios e o acionamento de medidas de salvaguarda e antidumping como mecanismos legítimos de proteção da política econômica comercial. Nesse sentido, pode-se dizer que o aumento da expectativa e exigência do mercado, as pressões do governo e o interesse dos investidores são motivos relevantes que levam a empresas a reconsiderar a forma de geração da inovação.

Em relação ao componente econômico "abertura da economia" as relações comerciais da indústria nacional com outros países apresenta-se como o principal desafio. Isso porque por um lado tem-se a modernização tecnológica da indústria com a importação de bens e, por Revista da Micro e Pequena Empresa, Campo Limpo Paulista, v.12, n.1 p.51-66, 2018 ISSN 1982-2537 
outro, a exposição do mercado interno à concorrência do mercado internacional. No entanto, é importante considerar os ganhos de eficiência agregados à obtenção de economias de escala e ganhos dos consumidores pela disponibilidade de maior variedade de produtos. Por isso pode-se dizer que a abertura da economia gera impactos positivos para o desenvolvimento de inovação ao permitir acesso a novos mercados e tecnologias, mas há desafios que envolvem as diferenças e condições locais existentes entre países como, por exemplo, os custos de capital e trabalho, retração do mercado interno, entre outros fatores (Aubert, 2002).

A despeito das percepções que a abertura da economia suscita existem países em que a abertura da economia afeta favoravelmente a sociedade, por exemplo, a representatividade das importações no Produto Interno Bruto (PIB) como é o caso da China, a Índia e os EUA. Neste quesito, o Brasil parece extremamente fechado, comparado a essas outras economias (Aubert, 2002).

O componente "abertura da economia" requer das organizações um olhar para o ambiente do seu entorno. Para Tidd et. al (2008) o componente "foco externo" envolve uma organização aberta ao seu ambiente externo. Desse modo, ela deve ser capaz de detectar sinais de ameaça ou oportunidade com o intuito de monitorar todo o seu ambiente. A orientação externa proporciona maiores oportunidades no dinamismo para uma organização inovadora, mas ela deve permear o pensamento organizacional em todos os níveis da empresa. Além disso, a comunicação clara e regular entre as pessoas pode oferecer inputs para a solução de problemas e o compartilhamento da inovação.

Em relação ao componente "ambiente legal e regulatório", no caso brasileiro, as leis antitruste relacionadas diretamente à inovação parecem ser aplicadas de forma inapropriada. Isso pode estar relacionado a um sistema judiciário fraco. Contudo, a concorrência de produtos importados reforça a necessidade de adequação do ambiente legal e regulatório voltado para a inovação.

Nesse sentido, Coutinho e Ferraz (1995) alertam que a exposição à concorrência de produtos importados é favorável, desde que o país apresente agilidade e capacitação para a utilização de instrumentos não-tarifários de proteção à indústria local contra a concorrência desleal. Cabe destacar que os países apresentam diferenças na estrutura econômica, valores e cultura que devem ser consideradas na formulação de medidas regulatórias e de incentivos à inovação. Mas é preciso ressaltar que existem peculiaridades no regime regulatório de cada país e por isso os mecanismos de incentivo à inovação devem promover a interação públicaprivada com vistas à inovação.

Considerando que as leis e regulações compõem a estrutura na qual as empresas operam, possuir regulações e padrões claros pode fornecer um forte indício para sustentar e orientar atividades inovadoras. Isso porque as leis e regulações "afetam o acesso à informação, direitos de propriedade, encargos tributários e administrativos e padrões ambientais". Elas são importantes para políticas de inovação, mas as necessidades de políticas são peculiares de setor para setor. As pesquisas sobre inovação podem revelar dados sobre esses temas por meio de fatores a respeito dos obstáculos à inovação (OCDE, 2005, p. 54).

Em relação ao componente "educação" o nível geral de educação da população é indispensável para a capacidade de desenvolvimento de uma economia, e, exerce forte contribuição para a capacidade de modernização e inovação tecnológica. A experiência internacional exemplifica que, além da alfabetização básica, é primordial oferecer a alfabetização funcional, formada por capacidades que permitem aos indivíduos enfrentarem os desafios do cotidiano (Aubert, 2002). Em complemento, Dahlman (2002) enfatiza que no Brasil há carência quanto à extensão do treinamento do pessoal nas empresas. Visando acompanhar as rápidas mudanças econômicas e tecnológicas as pessoas precisam passar por treinamento constante para fazer uso eficiente dos novos conhecimentos. Entende-se que a Revista da Micro e Pequena Empresa, Campo Limpo Paulista, v.12, n.1 p.51-66, 2018 ISSN 1982-2537 
educação secundária e superior intensifica o desenvolvimento de trabalhos técnicos e profissionais e isso reflete em ações que orientam o desenvolvimento da inovação.

Arbix e Miranda (2017) ressaltam que a falta de estratégia para a educação resulta no aumento da distância entre o Brasil e as nações que possuem algum protagonismo no contexto internacional. Mais especificamente, indicam que o caminho para um desempenho inovador adequado depende do esforço em educação e da elevação do patamar de Pesquisa e Desenvolvimento (P\&D) das organizações.

Observa-se que o componente "educação" apontado por Aubert (2002) está relacionado com o componente "indivíduos-chave" de Tidd et. al. (2008) ao considerarem a existência de um indivíduo-chave ou um grupo de pessoas fundamental para defender a inovação e oferecer entusiasmo na sua geração. Isso porque as pessoas são importantes fontes de conhecimento técnico. As pessoas e indivíduos chave imbuídos no processo de inovação podem contribuir positivamente na mobilização e superação de obstáculos dentro das empresas, e, nesse caso, são consideradas "patrocinadores organizacional" da inovação. Os autores afirmam que o êxito da inovação está associado ao fluxo de informação e comunicação promovido por indivíduos-chave dentro da estrutura informal da organização. Esses indivíduos atuam como gatekeepers buscando informações de variadas fontes e transmitindo-as para as pessoas certas dentro da organização.

O componente "desenvolvimento e treinamento de pessoas" indicado por Tidd et. al (2008) também está relacionado com os componentes "educação" e "indivíduos chave", tendo como interlocutores as pessoas envolvidas no processo de geração da inovação como parte de um programa de mudança mais amplo. Argumenta-se que quando inovações importantes são apresentadas, as pessoas, tendem a resistem à mudança por uma série de motivos, nem todos racionais ou claramente articulados.

Na realidade, a inovação demandará capacidades e habilidades que os indivíduos não possuem bem como trará desafios que não são totalmente compreendidos. Pode-se dizer que o componente "desenvolvimento e treinamento de pessoas" está relacionado ao componente "organizações que aprendem", uma vez que esses estão fortemente relacionados com o aprendizado das pessoas da organização. As rotinas que a organização desenvolve contribuem para o processo de aprendizagem entre as pessoas. Por isso, é importante estabelecer treinamento para o desenvolvimento da equipe num processo de aprendizagem formal baseado no ciclo de solução de problemas visando sustentar a aprendizagem para a inovação estável. Diante do exposto, propõe-se pensar ações voltadas ao desenvolvimento de pessoas como meio para reestabelecer a dinâmica inovativa num ciclo contínuo e permanente.

Verifica-se que o componente relacionado às pessoas na geração da inovação apóia-se no pressuposto de que a inovação é construída a partir das habilidades criativas e da capacidade de resolução de problemas que são de conhecimento de todos e não apenas de especialistas em P\&D. Para tanto, Tidd et al (2008) destaca que o componente "inovação com alto envolvimento das pessoas" requer o envolvimento do trabalho de equipe de pessoas em esforços de inovação que comumente está centrado em mudanças incrementais. No entanto, a cultura organizacional de apoio e estímulo de longo prazo sustenta as inovações incrementais contínuas.

Todas essas pretensões devem ocorrer concomitantemente no plano das ações voltadas para a inovação. Acredita-se que as ações para inovação seriam promovidas principalmente pela interação entre os participantes. O alto nível de participação pode expressar atitudes de partilha de conhecimento que, por vezes, pode estar subjetivo no processo de geração da inovação. A abertura à participação e interação das pessoas é também fator determinante da capacidade inovativa da organização com vistas à obtenção de vantagem competitiva.

Em complemento, é relevante destacar que o componente "visão compartilhada, liderança e desejo de inovar" também depende do envolvimento das pessoas. Tidd et. al Revista da Micro e Pequena Empresa, Campo Limpo Paulista, v.12, n.1 p.51-66, 2018 ISSN 1982-2537 
(2008), enfatizam que esse componente pode fortalecer o ambiente de geração da inovação se a empresa perceber a necessidade de mudança e buscar formas de assegurar que as pessoas com boas idéias sejam capazes de levá-las adiante, sem precisar abandonar a organização para fazê-la. Para isso, é necessário mudar a mentalidade e orientar o foco organizacional com a articulação de uma nova visão, o que é mais comum de se encontrar em organizações iniciantes ou em processo de recuperação.

A importância das pessoas na geração da inovação torna-se mais evidente ao se observar o componente "trabalho de equipe eficaz" caracterizado por equipes com diferentes perspectivas e flexibilidade no desenvolvimento da solução de problemas. Com isso, as equipes de pessoas podem colaborar para eliminar barreiras à inovação e aproximar limites dentro e fora da organização. Neste contexto, acredita-se que a base de conhecimento da equipe pode estabelecer regras de comportamento e padrões de solução de problemas rotineiros que resultariam em maior fluidez para o processo de geração da inovação.

De forma mais incisiva, Tidd et. al (2008) argumentam que a inovação requer um ambiente com "atmosfera criativa" para que o gestor possa intervir nas estruturas e processos e fornecer reforço aos estilos preferenciais de comportamento das pessoas na empresa que expresse a criatividade e conduza a uma cultura inovadora. Como resultado, entende-se, portanto, que as próprias relações estruturais e mercantis acabam sendo redefinidas.

$\mathrm{O}$ ambiente com "atmosfera criativa" requer gerenciar a criatividade dentro da organização em que o processo inicial demanda um significativo salto criativo, a continuidade do processo necessita de centenas de pequenos exercícios de detecção e resolução de problemas - cada um deles com um input criativo. Certamente, o primeiro irá precisar das habilidades ou da inspiração de um indivíduo específico, mas o último demandará input de muitas pessoas diferentes por um tempo ininterrupto.

É nesse contexto, que o componente comunicação extensiva parece ser um recurso para o desenvolvimento de um ambiente com atmosfera criativa. Tidd et. al, 2008 destacam que a comunicação extensiva envolve estabelecer canais e mecanismos de comunicação de modo claro e freqüente entre diferentes elementos e pessoas envolvidos no processo de inovação. A combinação de conjuntos de conhecimento compartilhados e distribuídos entre as pessoas na organização contribui para o sucesso da inovação.

A participação efetiva e consciente das pessoas na direção dos objetivos competitivos da empresa e do aprendizado contínuo só pode ser exigida de uma pessoa que tenha obtido satisfação em termos de sua relação com o trabalho. A competitividade requer das pessoas aptidões e atitudes que favoreçam sua maior integração no processo produtivo. Neste contexto, as empresas se deparam com o desafio para a implantação de processos de modernização associado à incapacidade de elaborar uma política de gestão de pessoas que promova a motivação e participação da força de trabalho em seus diversos programas (Coutinho \& Ferraz, 1995).

Diante dos comentários de Tidd et al. (2008) e Coutinho e Ferraz (1995) pode-de questionar até que ponto as organizações estão abertas a implantar um processo participativo de conhecimentos institucionalizados, com foco no desenvolvimento da inovação.

Outro componente que colabora para fomentar a inovação é a existência de "políticas de inovação" e, nesse caso, o Estado tem um papel importante no incentivo e apoio para encorajar a colaboração entre as organizações e a universidade (Aubert, 2002). A inovação fornece resultados sobre o produto, a produtividade e o emprego de especial interesse para as políticas de inovação, em âmbito nacional e para setores específicos e regiões. Por princípio, informações adequadas sobre as condições de sucesso da inovação colaborariam para o aperfeiçoamento de políticas que visam benefícios econômicos e sociais advindos da inovação (OCDE, 2005). O desenvolvimento de políticas de inovação com o estabelecimento de comissões e a presença de representantes das comunidades de negócios, especialmente das

Revista da Micro e Pequena Empresa, Campo Limpo Paulista, v.12, n.1 p.51-66, 2018 ISSN 1982-2537 
pequenas e médias empresas pode contribuir para identificar com clareza as áreas sobre as quais agir prioritariamente (Aubert, 2002).

Partindo dessa perspectiva, o Estado ao contemplar na política de inovação a determinação de estratégias com o mapeamento de áreas críticas, promove ou consolida as estratégias de inovação por meio da indução de decisões de investimento, financiamento e uso do poder de compra das empresas (Coutinho \& Ferraz, 1995). Nesse sentido, ressalta-se a importância das políticas de inovação serem construídas considerando as condições de competitividade das empresas no mercado interno e externo e as especificidades de cada país, com apoio público para pesquisa de forma a vincular o sistema público de inovação ao mercado.

Para aproximar o conhecimento e know-how existente na pesquisa acadêmica e pública é importante contar com o componente "programas e estruturas de Pesquisa e Desenvolvimento (P\&D)". O desafio permanece em aumentar o esforço de P\&D no setor privado, uma vez, que geralmente as empresas enquanto não descobrirem oportunidades fortuitas de inovação, decidem não investir em P\&D (Aubert, 2002). Entretanto, as empresas que investem em $P \& D$ interno obtêm vantagens relativas à geração direta de inovação, bem como vantagem de manutenção e ampliação de sua capacidade de reconhecer, assimilar e explorar informações externamente disponíveis (Coutinho \& Ferraz, 1995). Supondo-se mercados que funcionem eficientemente, uma estrutura descentralizada e flexível para a alocação de pessoas em atividade de $\mathrm{P} \& \mathrm{D}$ pode-se constituir, à longo prazo, a exploração adequada de conhecimento e vantagem competitiva.

Considerando o aspecto de estrutura, Tidd et al. (2008) afirmam que o componente "estrutura organizacional adequada" contribui para a geração da inovação uma vez que a empresa ao criar estruturas e processos organizacionais com maior interação entre diferentes funções e especialistas funcionais das áreas de produção, marketing, vendas, Pesquisa e Desenvolvimento (P\&D) entre outros trata a inovação como uma tarefa corporativa ampla e não apenas limitada à área de P\&D. Neste contexto, Parolim (2013) enfatiza a importância da participação de colaboradores em diferentes níveis estarem envolvidos a fim de se obter resultados com inovação, e não somente pessoas alocadas em P\&D. Isso sugere que o encadeamento das atividades inovativas pode minimizar deficiência nas competências para inovar.

Entende-se que a atividade de P\&D é importante para revelar as diferenças tecnológicas entre os países. Os dispêndios nesta atividade podem gerar resultados incertos, uma vez que não se sabe quais empresas se apropriarão do retorno de seus resultados, motivo pelo qual parte do setor empresarial não investe significativamente em P\&D. Em alguns casos, os investimentos públicos e privados em determinado setor empresarial podem geram benefícios em outros setores empresariais favorecendo e aperfeiçoando a capacidade de acumulação tecnológica das empresas (Tidd et al., 2008). De fato, a definição de ramos empresariais prioritários para investimento público em $\mathrm{P} \& \mathrm{D}$ deve ocupar espaço na política de inovação. No entanto, a natureza peculiar dos mercados também é um fator a ser considerado no apoio de esforços governamentais à $P \& D$. Pode-se dizer que isso reforça a importância da manutenção de investimentos em $\mathrm{P} \& \mathrm{D}$, o que implica em adotar medidas que permitam manter os rendimentos originários de forma adequada até a obtenção do retorno esperado com a comercialização da inovação.

Com o intuito de sintetizar a análise dos componentes do ambiente que contribuem para a geração da inovação é apresentado o quadro a seguir.

Quadro 04 - Análise dos componentes do ambiente para a geração da inovação.

Componentes

Resultado da análise

Revista da Micro e Pequena Empresa, Campo Limpo Paulista, v.12, n.1 p.51-66, 2018 ISSN 1982-2537 
Ambiente econômico e Ambiente legal e regulatório

Educação e Desenvolvimento
individual

Indivíduos-chave



Organizações que aprendem

Inovação com envolvimento
das pessoas
das pessoas

Trabalho em equipe e desejo de inovar

Ambiente ou atmosfera criativa



Comunicação extensiva

Programas de P\&D e estrutura
organizacional adequada

Fonte: Elaborado pelos autores.

A partir da análise dos componentes do ambiente interno e externo à organização para a geração da inovação, pode-se dizer que as especificidades técnicas, econômicas, sociais, entre outras que envolvem componentes devem ser consideradas na busca por vantagem competitiva por meio da inovação.

Revista da Micro e Pequena Empresa, Campo Limpo Paulista, v.12, n.1 p.51-66, 2018 ISSN 1982-2537
O foco aos aspectos do ambiente externo à organização é relevante para a geração da inovação porque ao monitorar o ambiente externo pode-se detectar ameaças e oportunidades para o processo de inovação. $\mathrm{O}$ monitoramento de aspectos econômicos e legais permitem a organização decidir como agir no mercado de forma competitiva.

A educação e o desenvolvimento individual são essenciais para o desenvolvimento de capacidades e habilidades de equipes envolvidas fundamentalmente em um processo contínuo e de longo prazo de geração da inovação.

Um indivíduo-chave ou uma equipe de pessoas que atuam como facilitadores na mobilização e superação de obstáculos do processo de inovação nas organizações contribui para a sua geração.

As organizações desenvolvem rotinas que levam ao aprendizado entre as pessoas. No entanto, é essencial contar um programa de treinamento formal e estruturado que promova o envolvimento de troca de informação e conhecimento de dentro e fora da empresa para a geração da inovação.

O alto nível de participação de uma equipe de pessoas em esforços de sustente, a longo prazo, as inovações incrementais contínuas.

O trabalho de uma equipe de pessoas com diferentes perspectivas, conhecimento e flexibilidade traz diferencial na forma de buscar soluções a problemas do processo de geração da inovação dentro e fora da organização.

A visão compartilhada, liderança e desejo de inovar trazem clara percepção à organização da necessidade de mudança. Essa pode ser promovida quando se tem bem definido o senso de propósito da organização para todos que fazem parte dela. Por isso, é importante dar atenção às boas ideias das pessoas envolvidas e interessadas na geração da inovação.

O ambiente criativo depende da forma como a organização gerencia o processo criativo das pessoas. É essencial ter como prática o processo de perceber e detectar diferentes habilidades ou inspiração das pessoas e as incentivá-las a expor suas ideias para criar algo novo.

A comunicação extensiva depende do desenvolvimento de canais e mecanismos de comunicação que sejam freqüentes entre diferentes pessoas e organizações envolvidos no processo de inovação.

Uma estrutura organizacional para a geração da inovação que articule funções e especialistas de diversas áreas da empresa e não apenas os envolvidos diretamente em P\&D, leva à possibilidade de resultados com inovação promissores. inovação depende, intrinsicamente, de uma cultura organizacional que 


\section{Considerações Finais.}

As organizações em um ambiente competitivo tendem a mobilizar esforços para inovação buscando melhorar a condição de competitividade, e obter retornos significativos em termos econômicos com a introdução da inovação no mercado. No entanto, a garantia de ciclos de inovação nas organizações depende da forma como a organização lida com os componentes do ambiente interno e externo. Argumenta-se que a inovação pode levar a resultados nem sempre previsíveis por isso é importante monitorar os componentes do ambiente interno e externo a fim de que se possa incorporar principalmente conhecimento externo em novos inventos da organização.

Observou-se que entre os componentes do ambiente que contribuem para a inovação evidenciados no decorrer do estudo, a orientação externa como parte do pensamento organizacional das pessoas da empresa contribui para a adoção de medidas de compensação de assimetrias nas empresas como, por exemplo, práticas de alíquotas de importação que permitam melhorar a condição de competitividade. É também importante contar com medidas regulatórias que atendam às variações das especificações e normas nacionais e internacionais e levem a diferentes padrões de competitividade.

Além disso, é amplamente destacado a importância das pessoas para a geração da inovação, visto que as diferentes perspectivas e flexibilidade no desenvolvimento da solução de problemas promove aprendizado ao combinar novos conhecimentos. Neste contexto, a organização deve estar aberta à mudança sendo capaz de promover a aprendizagem das pessoas a partir, por exemplo, de programas voltados à inovação com a participação dos colaboradores. A educação e o treinamento, o trabalho em equipe e o ambiente com atmosfera criativa são essenciais para estruturar atividades de inovação a longo prazo. Considerando que a estrutura organizacional tem grande influência no comportamento das pessoas é importante propiciar a comunicação e a hierarquia menos rígida para fomentar a criatividade e a inovação.

É premente a necessidade das organizações em adequar suas estruturas organizacionais tendo em vista a estrutura de mercado e a interação entre funções e especialistas funcionais de várias áreas da empresa e não apenas de $\mathrm{P} \& \mathrm{D}$, isso amplia a troca de conhecimento e o desenvolvimento da criatividade para inovação.

Como a inovação provoca impactos tecnológico e econômico no mercado e nas organizações, o que envolve desde os insumos empregados para a sua geração até o seu padrão de consumo, alinhar estruturas organizacionais existentes aos componentes do ambiente interno e externo pode promover a competitividade da organização. Ampliando essa análise sugere-se estudos que possam tratar da análise das condições ambientais internas e externas à organização alinhadas às estratégias para a inovação.

\section{Referências}

ARBIX, G. Diretrizes para o desenvolvimento de políticas de inovação no Brasil. Perspectivas n.9, 2017. Disponível em http://library.fes.de/pdffiles/bueros/brasilien/13240.pdf, acesso em: 12 de jan. 2017.

ARBIX, G.; MIRANDA, Z. Políticas de inovação em nova chave. Estudos Avançados, v. 31, n. 90, p. 49-73, 2017.

AUBERT, J. E. O que fazer para estimular a inovação no Brasil? In.: VELLOSO, João Paulo dos Reis. O Brasil e a economia do conhecimento. Rio de Janeiro: José Olympio, 2002.

BEAULIEU, C. M. G. Dos sistemas nacionais de pesquisa agrícola aos sistemas nacionais de inovação agrícola: a inserção dos institutos nacionais de pesquisa agropecuária. Tese 
(Doutorado em Política Científica e Tecnológica) 2013. 224 p. Universidade Estadual de Campinas, Instituto de Geociências, Campinas, 2013.

BESSANT, J.; TIDD, J. Inovação e empreendedorismo. Porto Alegre: Bookman, 2009.

CHESBROUGH, H. As novas regras de P\&D. Implementando a inovação. Harvard Business School, Rio de Janeiro: Elsevier, 2007.

COUTINHO, L. G.; FERRAZ, J. C. Estudo da competitividade da indústria brasileira. Campinas, SP: Papirus, Editora da Universidade Estadual de Campinas, 1995.

DAMANPOUR, F. Organization complexity and innovation. Management Science, v. 42, n.5, p. 693-716, 1996.

FREEMAN, C.; SOETE, L. A economia da inovação industrial. Campinas, SP: Editora da Unicamp, 2008.

KIM, L. Da imitação à inovação: a dinâmica do aprendizado tecnológico da Coréia. Campinas, SP: Editora da UNICAMP, 2005.

KLINE, S.; ROSENBERG, N. An overview of innovation. In.: LANDAU, R,; ROSENBERG, N. (Orgs.). The positive sum strategy. Washington: National Academy of Press, 1986.

LAPLANE, M. Inovações e dinâmica capitalista. In: CARNEIRO, R. (Org.). Os clássicos da economia (2). São Paulo: Ática, p. 60-67, 1997.

LANGRISH, J.; GIBBONS, M.; EVANS, W. G.; JEVONS, F. R. Studies of innovation in industry. Palgrave Macmillan UK, 1972

LUNDVALL,B. National systems of Innovation: towards a theory of innovation and interactive learning. Pinter: London, 1992

NELSON, R. R; WINTER, S.G. An evolutinary theory of economic change. Belknap Press of Harvard University Press: Cambridge, Massachusetts, 1982.

NELSON, R. R. National Innovation Systems. Oxford UP: Oxford, 1993.

[OCDE] ORGANIZAÇÃO PARA COOPERAÇÃO E DESENVOLVIMENTO ECONÔMICO (OCDE). Oslo Manual: diretrizes para coleta e interpretação de dados sobre inovação. 3. ed. Rio de Janeiro: Finep, 2005. Disponível em: http://www.finep.gov.br/images/apoio-e-financiamento/manualoslo.pdf. Acesso em: $28 \mathrm{de}$ ago. 2017.

[OCDE] ORGANIZATION FOR ECONOMIC CO-OPERATION AND DEVELOPMENT. Frascati Manual 2002: Proposed Standard Practice for Surveys on Research and Experimental Development, The Measurement of Scientific and Technological Activities. Paris: OECD, 2002. 
PAROLIM, S. R. H. Estudos multicasos sobre atividades inovativas. Revista Eletrônica de Administração, v. 48, n.3, p.608-620, jul./set. 2013. Disponível em: < http://www.scielo.br/pdf/rausp/v48n3/16.pdf. Acesso em: 21 de ago. 2016.

RIBERIO, G.; CHEROBIM, A. P. M. S. Environment and innovation: discrepancy between theory and research practice. RAI Revista de Administração e Inovação, v. 14, n. 1, p. 3040. 2017. Disponível em http://www.revistas.usp.br/rai/article/view/114449. Acesso em: 31 de jul. 2017

ROSS, J. A. Inovação interna. Implementando a inovação. Harvard Business School, Rio de Janeiro: Elsevier, 2007.

SCHUMPETER, J. A. Capitalismo, socialismo e democracia. Rio de Janeiro: Zahar, 1977

TIDD, J. Complexity, networks and learning:integrative themes for research on innovation management. International Journal of InnovationManagement, v. 1, n. 1, p. 1-22, 1997.

Innovation management in context: environment, organization and performance. Journal of Management Reviews, v. 3, n.3, p. 169-183, 2001.

TIDD, J.; BESSANT, J.; PAVITT, K. Gestão da inovação. Porto Alegre: Bookman, 2008. 